\section{In defence of (social) democracy: on health inequalities and the welfare state}

\author{
Clare Bambra
}

This issue features a comparative study by Guarnizo-Herreno et $a l^{1}$ on oral health inequalities in European welfare states. Looking at socioeconomic (occupational, educational and subjective social status) inequalities in functional dentition and edentulousness among adults aged 45 years and over, using data from the 2009 Eurobarometer, the authors conclude that relative and absolute health inequalities are present in all European welfare states $(n=21)$ and that they are not smaller (and may actually be largest) in the social democratic welfare states of Denmark, Finland, Norway and Sweden.

This is consistent with the findings of a growing body of comparative research into the international patterning of inequalities in health by welfare state regime, whereby the social democratic welfare states fare best in terms of general population health outcomes (eg, life expectancy of all social groups tends to be higher) but less well in terms of socioeconomic inequalities in health. $^{2} 3$ The findings of GuarnizoHerreno and colleagues ${ }^{1}$ are similar to those for self-reported health, ${ }^{4}$ oral quality of life $^{6}$ and obesity, smoking and mortality, ${ }^{7}$ for which 'no evidence for systematically smaller inequalities in health in countries in northern Europe (Scandinavia)' were found. ${ }^{7}$ Reviews of the political and welfare determinants of health have concluded similarly. ${ }^{3} 89$

This mismatch between doing well in overall health outcomes while doing less well in terms of reducing health inequalities has been termed a 'public health puzzle' or 'paradox', 81011 the nature of which is twofold: First, that there is an implicit expectation (or normative 'belief') within public health circles that better general health outcomes should be accompanied by smaller health inequalities; and second, that following public health theory, the social democratic welfare states with their more extensive, generous and egalitarian universal welfare

Correspondence to Professor Clare Bambra, Department of Geography, Wolfson Research Institute for Health and Wellbeing, Queen's Campus, Durham University, Stockton on Tees TS17 6BH, UK; clare.bambra@durham.ac.uk systems should have smaller health inequalities. In terms of the first issue, the naivety of this public health tenant has been exposed theoretically by Krieger, ${ }^{12}$ who argued that the social determinants of health are different from the determinants of health inequalities, and empirically by the work of Eikemo and colleagues, ${ }^{13}$ who found that countries with better health outcomes actually have larger relative health inequalities. ${ }^{10}$ The second aspect of the puzzle offers a more fundamental challenge to existing public health theory as aside from some support to the $\operatorname{artefact}^{13}$ (eg, the 'total mortality' method of Popham et $a l^{14}$ has found less evidence that health inequalities are larger in the social democratic welfare states) and health behaviour explanations (eg, smoking is more socially stratified in the social democratic countries), ${ }^{7}$ existing theories of health inequalities are unable to explain the relatively poor showing of the social democratic countries. ${ }^{2} 15$

Beyond the dry world of public health theory though, there are important political and policy repercussions of this puzzle: how can countries reduce or eliminate health inequalities if even Sweden has failed? However, whether the health patterns that we see in comparative social epidemiology should be regarded as a failure of the social democratic model is contestable on empirical and political terms. First, it was not always the case that the social democratic welfare states performed below expectations-until the 1980s, the few comparative studies that had been conducted into socioeconomic inequalities in health had concluded that the social democratic Scandinavian welfare states (particularly Norway and Sweden) had the smallest socioeconomic health inequalities. ${ }^{16}$ For example, a study by Valkonen, ${ }^{17}$ which examined educational inequalities in mortality in six European countries in the 1970 s, found that relative inequalities were smallest in Denmark, Norway and Sweden. It is only since the 1980s that studies have found the performance of the social democratic welfare states to be more questionable. ${ }^{18}$ So the patterns of health inequalities that we see now in European welfare states are from a period in which social democratic ideology and policies have been in relative decline. Denmark, Finland, Norway and Sweden have not been immune to the processes of globalisation, neoliberalism and welfare reform resulting in rising social inequality. ${ }^{19}$ The extent to which these welfare states still represent the social democratic ideal (or still differ significantly from the Bismarckian welfare states) is therefore contestable.

Second, while inequalities in health are not necessarily smaller in the social democratic welfare states, in absolute terms everyone does better. Taking the case of mortality among middle-aged men in Sweden, Lundberg and Lahelma ${ }^{20}$ comment that: 'On the basis of relative risk it would be possible to draw the conclusion that more than half a century of egalitarian policies have failed, since inequalities in mortality among middle-aged men are as large in Sweden as elsewhere in Europe. This sort of simplistic conclusion would ignore the fact that Swedish working class men have extremely good survival rates compared to similar men in other European countries, which in turn may very well result in the wide range of welfare state policies implemented since the 1930s.' The life expectancy of all socioeconomic classes is relatively higher than the equivalent groups in other developed countries, and premature mortality risks are also lower (especially in Norway and Sweden). ${ }^{20} 21$ This is reinforced by the work of Wilkinson and Pickett, ${ }^{22}$ which has shown that everyone does better in more equal countries. Comparative studies have also shown that the most vulnerable social groups-the old, ${ }^{23}$ the sick $^{24}$ and children $^{25}$-fair better in the social democratic welfare states, ${ }^{26}$ and higher social expenditure on welfare has health benefits for the least educated men and women. ${ }^{27}$ The scale of social deprivation (and therefore who experiences the worst health) varies by country with, for example, the lowest educated in the social democratic countries amounting to approximately $15 \%$ of the population as opposed to approximately $40 \%$ of the population in Anglo-Saxon countries $^{1}$-more people therefore experience the sharp end of health inequalities in England than in Sweden.

Finally, the comparison of absolute and relative health inequality also raises important normative and political issues about whether the role of the social democratic (and to some extent the other) welfare states is to improve the status of those at the very bottom of society or whether it is about promoting more general equality. Implicitly, cross-national 
research to date has tended to favour the latter view; however, it is possible to suggest that it should move beyond relative comparisons and focus instead on absolute ones. ${ }^{2}$ This would perhaps also enhance the policy relevance of such research; after all, as $\operatorname{Rose}^{28}$ famously commented, 'relative risk is not what decision-taking requires ... relative risk is only for researchers; decisions call for absolute measures'. Future comparative research could therefore benefit from examining the absolute health of the most marginalised, poorest and vulnerable within different types of welfare state, and from this find meaningful new ways to reduce inequalities within all advanced welfare states.

Inspiration can still be drawn from social democracy.

\section{Competing interests None.}

Provenance and peer review Commissioned; internally peer reviewed.

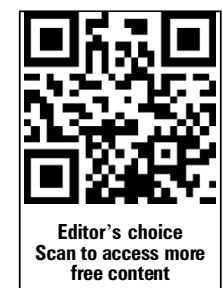

To cite Bambra C. J Epidemiol Community Health 2013:67:713-714.

Received 5 June 2013

Accepted 6 June 2013

Published Online First 27 June 2013

J Epidemiol Community Health 2013;67:713-714. doi:10.1136/jech-2013-202937

\section{REFERENCES}

1 Guarnizo-Herreno C, Watt R, Pickhart H, et al. Socio-economic health inequalities in oral health in different European welfare state regimes. J Epidemiol Commun Health 2013;67:728-35.

2 Bambra C. Health inequalities and welfare state regimes: theoretical insights on a public health 'puzzle'. J Epidemiol Commun Health 2011;65:740-5.

3 Muntaner C, Borrell C, Edwin N, et al. Review article: politics, welfare regimes, and population health: controversies and evidence. Sociol Health IIIn 2011:33:946-64

4 Eikemo T, Bambra C, Joyce $\mathrm{K}$, et al. Welfare state regimes and income related health inequalities: a comparison of 23 European countries. Eur J Public Health 2008;18:593-9.

5 Eikemo TA, Huisman M, Bambra C, et al. Health inequalities according to educational level under different welfare regimes: a comparison of 23 European countries. Sociol Health IIIn 2008:30:565-82.

6 Sanders AE, Slade GE, John MT, et al. A cross-national comparison of income gradients in oral health quality of life in four welfare states: application of the Korpi and Palme typology. J Epidemiol Commun Health 2009;63:569-74.

7 Mackenbach J, Stirbu I, Roskam A-JR, et al. Socioeconomic Inequalities in Health in 22 European Countries. N Engl J Med 2008;358: 2468-81.

8 Dahl E, Fritzell J, Lahelma E, et al. Welfare state regimes and health inequalities. In: Siegrist J, Marmot M. eds. Social inequalities in health. Oxford: Oxford University Press, 2006:193-222.

9 Beckfield J, Krieger N. Epi + demos + cracy: linking political systems and priorities to the magnitude of health inequities - evidence, gaps, and a research agenda. Epidemiol Rev 2009:31:152-77.

10 Huijts T, Eikemo TA. Causality, selectivity or artefacts? Why socioeconomic inequalities in health are not smallest in the Nordic Countries. Eur J Public Health 2009;19:452-3

11 Mackenbach J. The persistance of health inequalities in modern welfare states: the explanation of a paradox. Soc Sci Med 2012;75:761-9.

12 Krieger N. Ladders, pyramids and champagne: the iconography of health inequities. J Epidemiol Commun Health 2008;62:1098-104.

13 Eikemo TA, Skalická V, Avendano $\mathrm{M}$, et al. Variations in relative health inequalities: are they a mathematical artefact? Int J Equity Health 2009;8:32.

14 Popham F, Dibben C, Bambra C. Are inequalities in mortality really not the smallest in the Scandinavian welfare states? A comparative total inequality analysis of life expectancy in 37 countries. J Epidemiol Commun Health 2013:67:412-8.

15 Vagero D, Illsley R. Explaining health inequalities: beyond Black and Barker. Eur Sociol Rev 1995:3:219-41.

16 Black D. Inequalities in health: The Black Report. London: Pelican, 1980.

17 Valkonen T. Adult mortality and level of education: a comparison of six countries. In: Fox AJ. ed. Health inequalities in European countries. Aldershot: Gower, 1989:142-60.

18 Mackenbach J, Kunst A, Cavelaars AEJM, et al. Socioeconomic inequalities in morbidity and mortality in Western Europe. Lancet 1997:349:1655-9.

19 Kvist J, Fritzell J, Hvinden B, et al. (eds). Changing social equality: the Nordic welfare model in the 21st century. Bristol: Policy Press, 2011.

20 Lundberg O, Lahelma E. Nordic health inequalities in the European context. In: Kautto M, Fritzell J, Hvinden B, Kvist J, Uusitalo H. eds. Nordic welfare states in the European context. London: Routledge, 2001:42-65.

21 Fritzell J, Lundberg 0 . Fighting inequalities in health and income: one important road to welfare and social development. In: Kangas 0, Palme J. eds. Social policy and economic development in the Nordic Countries. New York: Palgrave Macmillan, 2005:164-85.

22 Wilkinson R, Pickett K. The spirit level: why more equal societies almost always do better. London: Penguin, 2009.

23 Avendano $\mathrm{M}$, Jurges $\mathrm{H}$, Mackenbach JP, et al. Educational level and changes in health across Europe: longitudnal results from SHARE. J Eur Soc Policy 2009;19:301-16.

24 van der Wel K, Dahl E, Thielens K. Social inequalities in sickness: European welfare states and non-employment amongst the chronically sick. Soc Sci Med 2011:73:1608-17.

25 Zambon A, Boyce W, Cois E, et al. Do welfare regimes medicate the effect of socioeconomic position on health in adolescence? A cross-national comparison in Europe, North America and Israel. Int J Health Serv 2006;36:309-29.

26 Bambra C. Work, worklessness and the political economy of health. Oxford University Press, 2011.

27 Dahl $\mathrm{E}$, van der Wel K. Educational inequalities in health in European welfare states: a social expenditure approach. Soc Sci Med 2013;81:60-9.

28 Rose G. The strategy of preventive medicine. Oxford: Oxford University Press, 1992. 